\title{
Raturwifienidafflide BSTementarbiidjer.
}

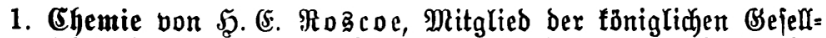

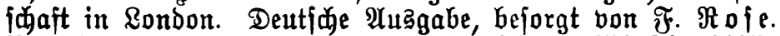

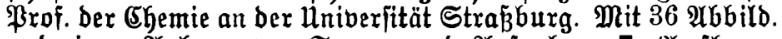

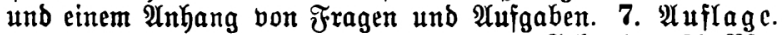

Bebunden 80 Pfg.

2. Bhyjif bon Balfour Stetoart, Brojeffor ber Bhyfif in

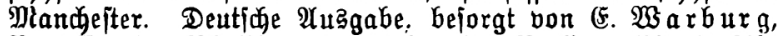
Profeffor ber Phyfif an ber llniverität $\mathfrak{B e r l i n . ~ M i t ~} 48 \mathfrak{A} \mathfrak{b}=$ billunget und einem $\mathfrak{A}$ nhang von Fragen und $\mathfrak{A} u$ fgaben. 5. ver= befierte $\mathfrak{A}$ uflage.

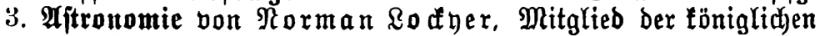

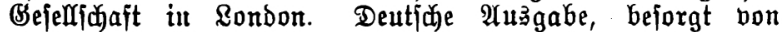

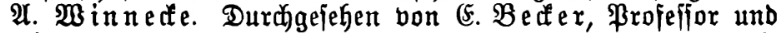
Direftor ber Raif. Ulnib.=Sternmarte zu Strafiburg. Mit

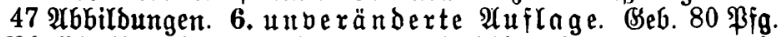

4. Phyjtfalifde (Seographie von $\mathfrak{A}$. Seifie, \$roj. Der Beologie

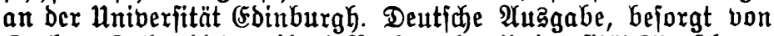

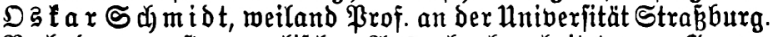

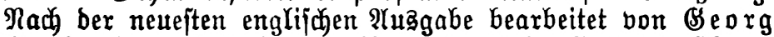

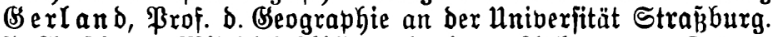
5. $\mathfrak{A} u f \mathfrak{l}$ age. Mit $21 \mathfrak{A b b i l b . ~ u n d ~ e i n e m ~} \mathfrak{A}$ hang bon fragen und Aufgaben.

Sebunden 80 łfg.

5. Senlogie bon $\mathfrak{A}$. Se ifie. Deutide $\mathfrak{A} u$ gagabe, bejorgt von

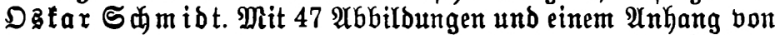

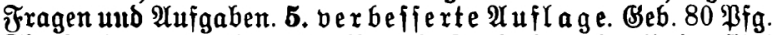

6. 7. Tierfunbe von $\mathfrak{A}$. (S oet te, Prof. ठ. 3oologte an ber Hniverfität Straß̧burg. Mit 65 Abbiloungen. 2. bur

Sebunden $\mathfrak{M}$. 1.60 .

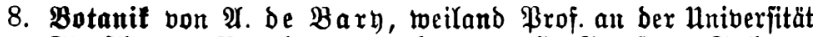

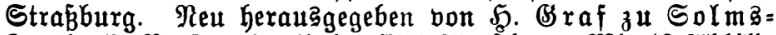

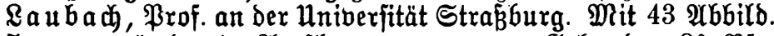
5. unveränderte $\mathfrak{A} u f l a g e$.

Bebunden 80 Pig.

9. Mitueralogie von $\mathbb{R a r l} \mathfrak{F}$. Peter $\overline{3}$, \$rof. ber Mineralogie und (Beologie an ber Ulniberjîtät Braz. Mtit 46 Mbbilb. Durct)=

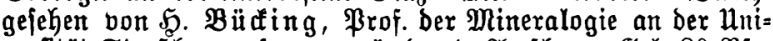

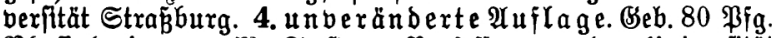

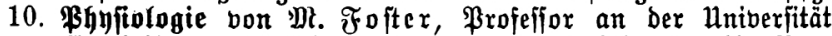

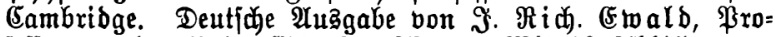

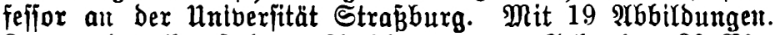
3. neu burdgefehene $\mathfrak{A} u \mathfrak{l}$ lage. Sebunben $80 \mathrm{Pfg}$.

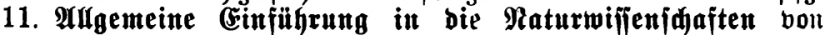

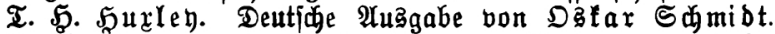
Durabgejehen von Paul Sgenjel, a.=o. Prof. an ber Hniv. Soibelberg. 4. $\mathfrak{A} \mathfrak{u} \mathfrak{i l a g e . ~}$

Sebunben 80 Pfg. 


$$
\Sigma
$$





\title{
Maturnifienianaflide (Elementarbilder.
}

\section{Titet tild}

bott

\author{
A.
}

ßrofefior ber 300 logie an ber Aniverität straßumg.

mit 65 Mboitoungen.

Biveite Surd)gefehene Âtuflage.

Straßjurg.

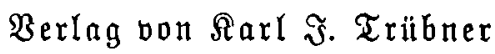
1904.

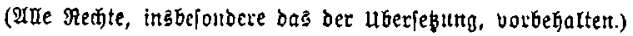


Drutt bon $\mathfrak{M}$. DuMnort=Sdauberg, Straßburg. 